\title{
periferio
}

\section{O SKYPE NA PESQUISA PÓS-COLONIAL: REINVENÇÕES DE UM PESQUISADOR “ESTRANGEIRO”}

\author{
Ana Paula Pereira Marques de Carvalho ${ }^{1}$
} Universidade do Estado do Rio de Janeiro

\section{Resumo}

O presente texto visa contribuir para as reflexões acerca das interfaces tecnológicas nas pesquisas acadêmicas. De fato, nos dias atuais, é crescente a possibilidade de uso de equipamentos que intermediem a relação pesquisador - pesquisado, quer seja nas entrevistas ou discutir o próprio objeto de pesquisa através de ambientes virtuais. Utilizei o Skype nas entrevistas da minha pesquisa de Mestrado e o movimento de sentidos que se potencializou através da referida interface viabilizou a problematização da relação pesquisador - pesquisado, possibilitando discussões sobre o processo fugidio e imprevisível que envolve o contato com o Outro. Assim, em diálogo com Homi Bhabha, discutirei, neste artigo, o movimento do pesquisador sob a perspectiva do "estrangeiro", uma noção que Bhabha (2013) utiliza em referência a Salman Rushdie, autor do livro Versos Satânicos, para ressaltar que os atores migrantes - políticos - contribuem para a produção de sentidos contínua. Neste sentido, o pesquisador, como estrangeiro, enredado num processo investigativo fluido, impossível de ser controlado, envolve-se nas significações sobre o encaminhamento das investigações e, de maneira salutar, disputa sentidos sobre o encaminhamento da pesquisa com todos os envolvidos no processo.

Palavras-chave: tecnologia; metodologia de pesquisa; "estrangeiro"

\footnotetext{
${ }^{1}$ Doutoranda pelo Programa de Pós-graduação em Educação da Faculdade de Educação da UERJ, na linha de pesquisa Currículo, Sujeitos, Conhecimento e Cultura. Mestre em Educação - ênfase em Tecnologia e Currículo - também pelo Programa de Pós-graduação em Educação da Faculdade de Educação da UERJ, na linha de pesquisa Currículo, Sujeitos, Conhecimento e Cultura.
} 


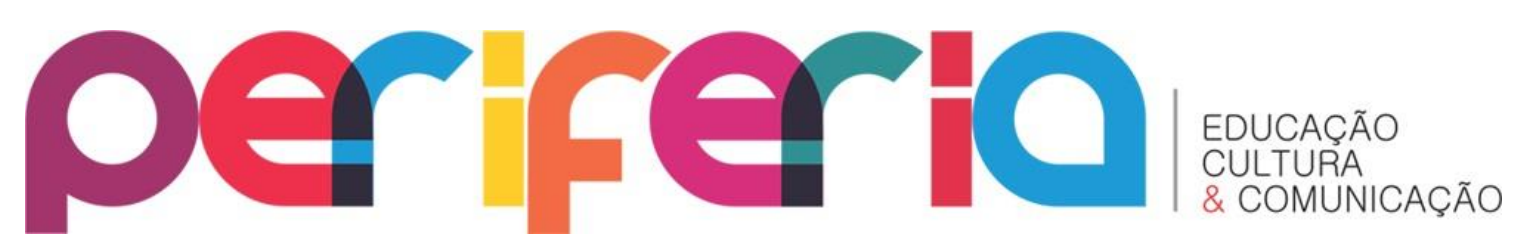

\title{
THE SKYPE IN POST-COLONIAL RESEARCH: REINVENTIONS OF A “FOREIGNER” RESEARCHER
}

\begin{abstract}
The present text aims to contribute to the reflections about the technological interfaces in the academic researches. In fact, nowadays, the possibility of using equipment that mediates the researched - researcher relationship is growing, whether in interviews or discussing the research object itself through virtual environments. I have used Skype in the interviews of my Master's research and the movement of meanings that was potentialized through that interface enabled the problematization of the researcher - researched relationship, allowing for discussions about the fleeting and unpredictable process that involves contact with the Other. Thus, in dialogue with Homi Bhabha, I will discuss in this article the movement of the researcher from the perspective of the "foreigner", a notion that Bhabha (2013) uses in reference to Salman Rushdie, author of the book Satanic Verses, to emphasize that the actors Migrants - politicians - contribute to the continuous production of meanings. In this sense, the researcher, as a foreigner, entangled in a fluid investigative process, impossible to be controlled, is involved in the meanings about the direction of the investigations and, in a salutary manner, disputes the direction of the research with all those involved in the process.
\end{abstract}

Keywords: technology, research methodology, "foreigner" 


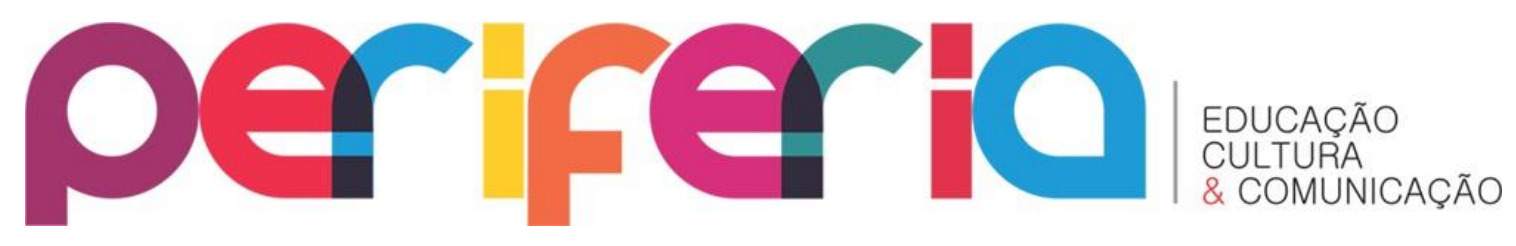

Minhas pesquisas de cunho institucional e individual têm me instigado a refletir sobre a relação entre teoria e metodologia que se faz necessária na análise do objeto de pesquisa. De fato, esse é um aspecto de suma importância para o processo investigativo e, muitas vezes, de grande dificuldade para quem as produz, pois a dinâmica teórico-metodológica implica no entendimento da metodologia como um certo modo de perguntar, de interrogar, formular questões e construir problemas que, correlacionados à teoria, produzem informações. Não é um processo simples e, na atualidade, com as práticas sociais mediatizadas por artefatos tecnológicos, deparamonos com mais um componente metodológico que desafia os pesquisadores a lidar com um universo tecido pelas tecnologias digitais de informação e comunicação - TDIC - e pelas tecnologias móveis sem fio - TMSF.

Paraíso (2013) oportuniza reflexões sobre o entrelace entre teoria e metodologia em tempos de mudanças significativas no próprio campo da educação - área do meu interesse de investigação - em que se faz necessário a criatividade na pesquisa. Concordo com a autora que o prazer na investigação e o despojamento do pesquisador para novas descobertas, para novas experiências, sejam fundamentais na fluidez da criatividade e enfatizo a importância da construção de estratégias para responder às questões de pesquisa. Mas, ao mesmo tempo, é preciso que os pesquisadores se movam daqui para lá, de lá para cá, buscando a reconstrução dos métodos e a proposição de tantos outros que viabilizem reflexões acerca da problemática proposta.

Em meio à dificuldade em articular teoria e prática - não passei incólume por esse processo -, estive imersa, e vivenciei meus próprios dizeres pós-coloniais, o que me permitiu refletir sobre os sentidos do trabalho do pesquisador e sobre as possibilidades de reinvenção da verdade em relação às metodologias de pesquisa (PARAíso, 2013). A opção pelo aporte teórico póscolonial abriu caminhos para reflexões sobre a minha trajetória cuja opção metodológica foram as entrevistas, via Skype. Ao me aprofundar na teoria e 


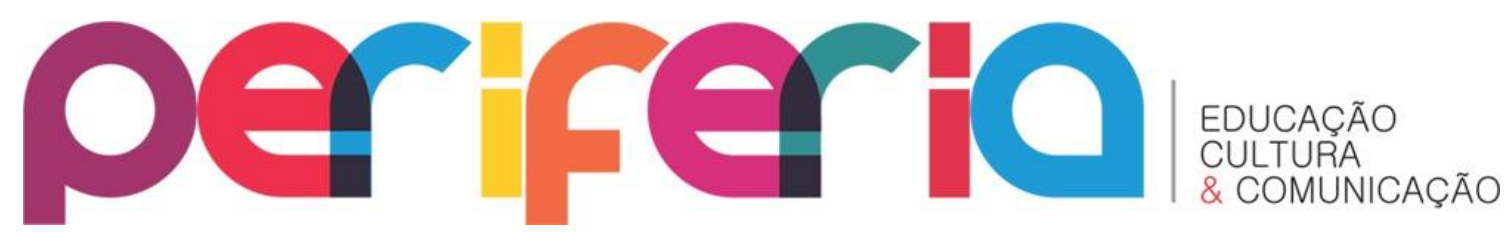

experienciar o contato com os entrevistados, refleti sobre as relações entre os sujeitos em constante processo de negociação, ou seja, pesquisador e pesquisado estão imersos num jogo de diferenças em que há disputas de sentidos sobre o objeto de pesquisa. Sentidos esses que se hibridizam não como uma mistura de ideias, pura e simples, mas um processo de partilha de sentidos, que não é puro e tampouco transparente. Os sentidos sobre as questões da pesquisa transcorrem em espaços intervalares, entre as concepções do pesquisador e do pesquisado num jogo salutar, com o deslocamento de ambos, uma vez que estão também mergulhados em realidades descontínuas, fragmentadas, que reconfiguram os sujeitos e ressignificam suas próprias identidades, no trânsito de pesquisador a pesquisado e de pesquisado a pesquisador.

Vejo essas peculiaridades espaciais como sintomas e expressões de um dilema novo e historicamente original, que envolve nossa inserção como sujeitos individuais em uma série multidimensional de realidades descontínuas radicais, cujas molduras vão desde os espaços da vida privada burguesa que afinada sobrevivem através de todos os estágios intermediários, até o inimaginável descentramento do capital global... a chamada morte do sujeito... o descentramento fragmentado e esquizofrênico [do Eu]... a crise do internacionalismo socialista e as enormes dificuldades táticas de coordenar... ações políticas locais com outras nacionais ou internacionais; tais dilemas políticos urgentes são todos funções imediatas do novo espaço internacional em questão (BHABHA, 2013).

0 pesquisador está mergulhado numa série multidimensional de realidades descontínuas. Bhabha (2013), principal autor pós-colonial que subsidia minhas pesquisas, cita essa passagem para destacar que os processos culturais estão marcados por um novo espaço internacional em que as migrações em massa, as relações inter-raciais e os meios de comunicação colaboram para cisões e deslocamentos de culturas locais, abrindo um terceiro espaço, o híbrido que nos marca em função das diferenças que o tempo todo negociamos com o Outro. Ainda que eu não esteja tratando 


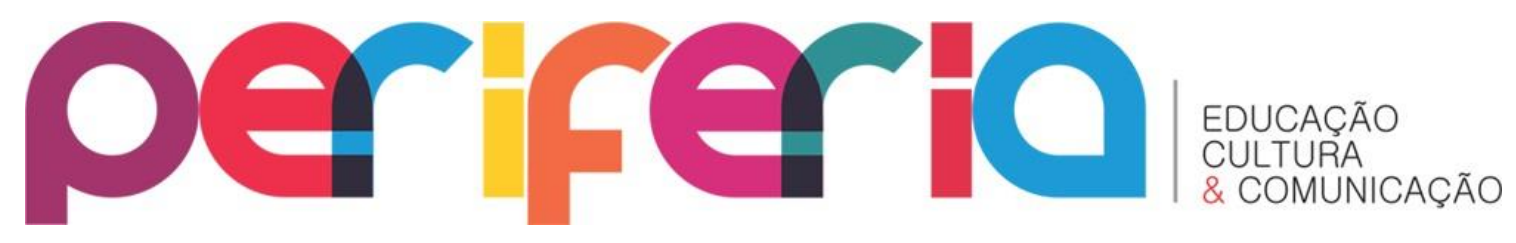

especificamente de fluxos migratórios, destaco que pesquisador e pesquisado vivenciam essas novas relações. Neste sentido, um conceito-chave para a problematização dessa relação sob o aporte pós-colonial é a noção de estrangeiro (BHABHA, 2013).

O termo estrangeiro é utilizado por Bhabha (2013), em diálogo com Salman Rushdie que, segundo o autor pós-colonial, ao escrever o livro Versos Satânicos, subverte a autenticidade do Corão através do ato de tradução cultural quando relata a história de dois indianos, atores, migrantes na Inglaterra, que se metemorfoseiam - um em diabo e o outro em anjo - após sofrerem um acidente de avião e caírem no solo da Inglaterra, sem qualquer lesão. "Ele recoloca a intencionalidade do Corão, repetindo-a e reinscrevendo-a no cenário do romance das migrações e diásporas culturais do pós-guerra" (BHABHA, 2013, p. 356). Esse é o motivo pelo qual, na opinião do Bhabha (2013), o livro foi considerado uma blasfêmia pelos muçulmanos. A blasfêmia reside na abertura de um espaço de contestação discursiva que coloca a autoridade do Corão dentro de uma perspectiva de relativismo histórico e cultural (BHABHA, 2013).

Ao contrário de Derrida e Man, estou menos interessado na
fragmentação metonímica do "original". Estou mais
comprometido com o elemento "estrangeiro" que revela o
intersticial, que insiste na superfluidade têxtil de dobras e
pregas e que se torna o "elemento instável de ligação", a
temporalidade indeterminada do intervalar, que tem de
participar das condições pelas quais "o novo entra no mundo"
(BHABHA, 2013, p. 358).

Bhabha (2013) retoma o conceito de "estrangeiridade" de Benjamin (apud BHABHA, 2013) para destacar que os elementos estrangeiros contribuem para um estado constante de constestação, destruindo as estruturas de referência do sentido do original, não simplesmente negando, mas negociando sentidos em meio à performance da tradução cultural. 0 estrangeiro é um elemento instável de ligação que revela o "presente" da tradução, entendida como o ato de viver em fronteiras, uma transição que não é tranquila, 


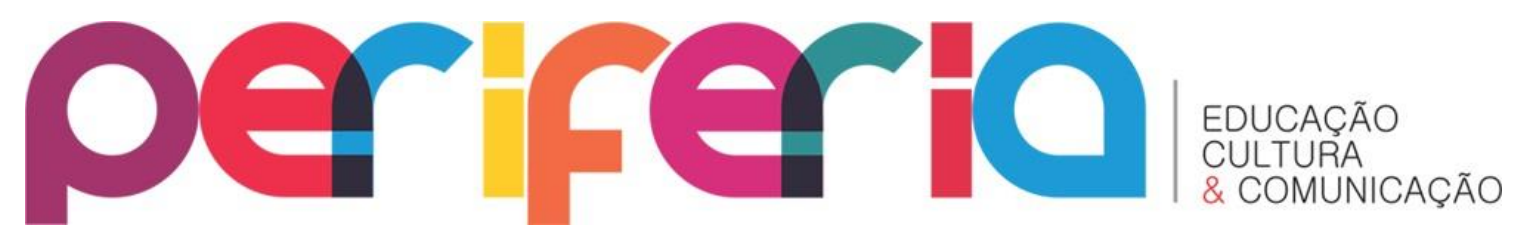

tampouco uma continuidade consensual, mas sim a configuração da reescrita das experiências que se movimentam em constante processo de diferimento.

Posto isso, considerar o pesquisador como um elemento estrangeiro significa compreendê-lo como partícipe da performance da tradução cultural em constante estado de contestação e fluxo de sentidos sobre o objeto da pesquisa, no contato com o pesquisado, no caso os entrevistados. 0 pesquisador contribui para a produção de uma linguagem in actu que dessacraliza o pedagógico, compreendido como a tradição, e resgata o performático, híbrido, que surge continuamente acerca das possibilidades do que está sendo pesquisa (BHABHA, 2013).

Neste movimento, os estrangeiros - pesquisadores - estão mergulhados no turbilhão das arenas de conflito, enredados nas negociações ocasionadas pelo dinamismo da enunciação que descanoniza o original do texto objeto de pesquisa, fragmentando-o (BHABHA, 2013). Atores políticos que na agência da estrangeiridade participam da iteração performática e contribuem para a produção de imagens no jogo das ambivalências e disputas de sentidos em relação às possibilidades da pesquisa (BHABHA, 2013).

Assim, este artigo se propõe a problematizar a utilização da interface do Skype nas entrevistas, discutindo o papel do pesquisador como estrangeiro, numa dinâmica em que o inesperado sempre acontece e provoca a reinvenção do pesquisador - que deve estar aberto para isso - a todo momento.

\section{A TRAJETÓRIA DA PESQUISA SOB O APORTE PÓS-COLONIAL}

Em minha pesquisa de Mestrado, o objetivo era suscitar questões acerca da tríade política, currículo e tecnologia nas escolas públicas do Município do Rio de Janeiro, detidamente na gestão do ex-Prefeito Eduardo Paes $^{2}$. Os objetos de estudo foram uma plataforma online, chamada

\footnotetext{
${ }^{2}$ A gestão do Prefeito Eduardo Paes começou em 2008. Ele foi reeleito em 2012 e permanecerá no cargo até 2016.
} 


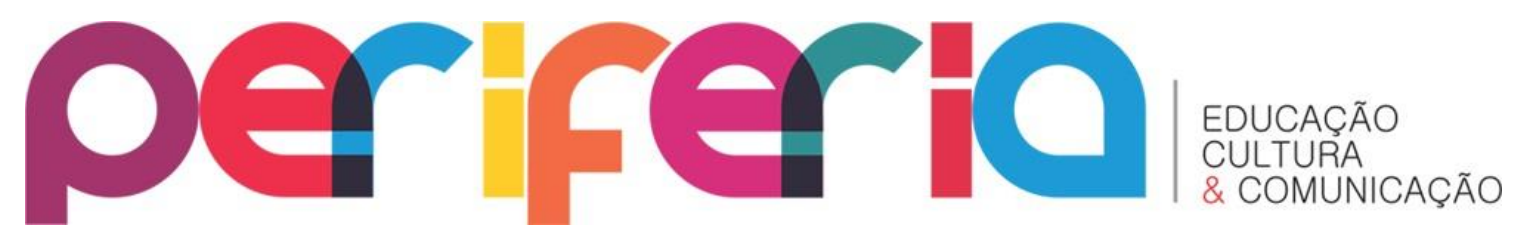

Educopédia, criada na gestão do referido Prefeito, e seus Embaixadores que eram os próprios professores da Rede municipal de ensino que se candidatavam a essa atividade - remunerada -, também criada na referida gestão, a fim de dinamizar a plataforma nas escolas.

A discussão foi tecida sob o aporte de vários recursos: análise dos documentos, informações via internet, via Facebook, blogs e conversas informais. Contudo, optei pela técnica de entrevistas como estratégia metodológica principal, pois, ao longo do investigativo, senti que era necessário o contato com o Professor Embaixador da Educopédia para problematizar o irromper do "novo" no processo de produção curricular. Um "novo" que não se caracteriza por um ineditismo de sentidos, ideias, concepções, mas sentidos híbridos num contexto político marcado pela articulação entre currículo e tecnologia como indicativo de qualidade. As entrevistas foram realizadas com 11 professores da Rede Municipal do Rio de Janeiro - entre Embaixadores e não Embaixadores - que ministravam aulas em bairros distintos do Rio de Janeiro.

O Skype foi a interface mais utilizada para as entrevistas, ainda que alguns diálogos tenham ocorrido via chat do Facebook. Minha intenção inicial era utilizar o Facebook apenas para os contatos iniciais e proceder às entrevistas com os professores Embaixadores e outros professores de maneira presencial. Contudo, as primeiras professoras contactadas para as entrevistas - professoras que já tinham exercido as atividades de Embaixador em suas escolas - solicitaram que a conversa acontecesse via Skype, o que provocou uma reflexão no grupo de pesquisa, do qual faço parte, sobre a interface tecnológica diante de uma perspectiva teórico-metodológica que se subsidiava no discursivo, ou seja, no entendimento do grupo, sentidos seriam produzidos numa relação de alteridade, numa produção dialógica em que o pesquisador assume uma responsabilidade em relação ao Outro. Há palavras, verbalizadas e não verbalizadas, entre pesquisador e pesquisado que merecem atenção e, nessa relação de responsabilidade, há um aspecto de suma importância a ser destacado: o pesquisador não é o detentor do conhecimento (BAHKTIN, 2006). 


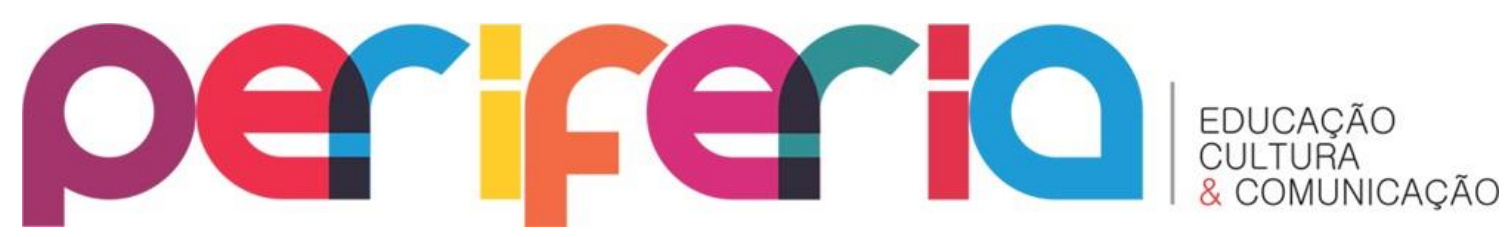

Assim, sob a perspectiva do discursivo, eu pretendia problematizar as diferentes leituras de uma proposta de articulação entre tecnologia e currículo e os movimentos de sentido que fluem por entre espaços intersticiais, estando atenta para os sentidos recorrentes nas falas em relação à Educopédia e para as ideias marcantes que circulam nas escolas sobre as possibilidades da tecnologia. Minha intenção era mergulhar no fluxo de sentidos, a fim de discutir o movimento do entrevistado na tensão entre aquilo que está sendo proposto coletivamente, em termos de política, e o que se produz na especificidade das escolas e no trabalho dos Embaixadores. E o Skype neste processo? Eu comentei sobre o pedido das entrevistadas no grupo de pesquisa e surgiram várias questões interessantes que entendo como um deslocamento sobre o significado de entrevista numa pesquisa com aportes pós-coloniais, provocando, no grupo, reflexões acerca de outras possibilidades de contato entre as pessoas de uma maneira não presencial.

0 pesquisador precisa considerar as novas formas de comunicação interpessoal, geralmente gratuitas, dinamizadas através da difusão e da popularização da internet, que trazem desafios metodológicos e transformam o cenário das pesquisas (JODELET, 2003 apud COSTA, DIAS e LUCIO, 2003).

Essas novas formas de comunicação podem ser assincrônicas e outras sincrônicas. Nas assincrônicas, a troca de mensagens entre interlocutores ocorre com intervalos de tempo não previsíveis. É o caso dos programas de $e$ mail, dos fóruns de discussão, etc. Já nas sincrônicas, a troca de mensagens entre interlocutores acontece instantaneamente, ou seja, em tempo real (COSTA, DIAS e LUCIO, 2009). Um exemplo bastante popular atualmente é o WhatsApp Mensenger ${ }^{3}$, uma aplicação multi-plataforma de mensagens instantâneas para smartphones. Através do WhatsApp, os usuários podem

\footnotetext{
3“"WhatsApp Messenger é uma aplicação multi-plataforma de mensagens instantâneas e chamadas de voz para smartphones. Além de mensagens de texto, os usuários podem enviar imagens, vídeos e mensagens de áudio de mídia. O software cliente estádisponível para Android, BlackBerry OS, iOS, Symbian, Windows Phone e Nokia." Disponível em: http://pt.wikipedia.org/wiki/WhatsApp. Acesso em: 10 jul. 2014.
} 


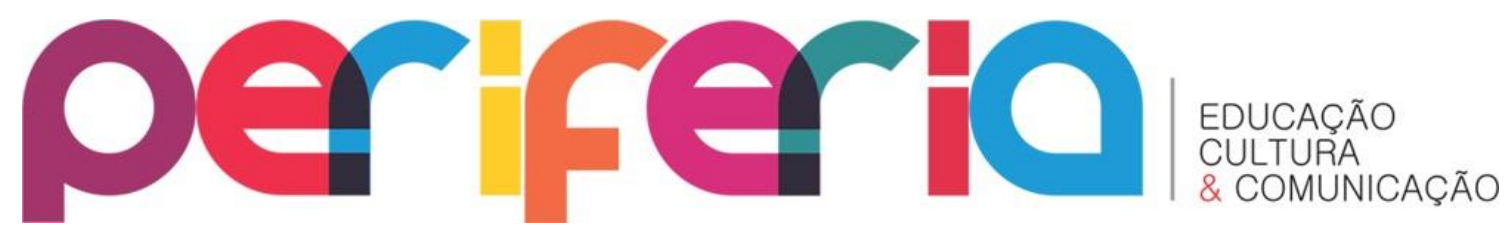

enviar mensagens de texto, bem como imagens, vídeos e mensagens de áudio de mídia através de seus telefones celulares.

Vivenciamos também relações intermediadas pelas redes sociais Facebook, Twitter, Google+, Linkedin, Instagram, Pinterest (AS REDES SOCIAIS MAIS USADAS DO MUNDO, 2017) - que compõem a cultura digital na qual estamos enredados.

Braga e Gastaldo (2012) observam que Queiroz (1991 apud BRAGA e GASTALDO, 2012) propôs uma discussão em seu livro "Variações sobre a técnica de gravador no registro da informação viva" como uma importante vertente metodológica da pesquisa em ciências humanas e sociais: as histórias de vida ou história oral. Da mesma maneira, os autores acreditam que a introdução de um canal de vídeo em um meio de comunicação interpessoal traz uma série de consequências, não apenas para a vida cotidiana de quem o utiliza, mas também para a pesquisa que adota esse meio como instrumento de trabalho ou objeto de investigação.

Os autores apresentam, também, as características do Skype e destacam a rápida popularização do aplicativo que o colocou como um elemento fundamental para compreender as novas configurações da midiatização das relações interpessoais na contemporaneidade.

O Skype é um aplicativo para computadores que combina tecnologia VoIP com a organização de uma base de dados de participantes, semelhante às redes sociais. 0 termo VolP é uma sigla que significa Voice Over Internet Protocol". O website How Stuff Works dá a seguinte definição: "VolP é um método para tomar sinais de áudio analógico, como os que você ouve quando fala ao telefone, e transformá-los em dados digitais que podem ser transmitidos pela Internet" (HOW STUFF WORKS (TRADUÇÃO DOS AUTORES)).

O Skype permite que se façam chamadas usando o microfone e as caixas de som de um computador, ligando tanto para outros computadores conectados quanto para telefones fixos e móveis do mundo todo, usando o sistema SkypeOut...além do sistema de mensagem instantânea (conveniente em caso de conexão fraca), o aplicativo ainda permite teleconferências somente com voz, conectando até 100 pessoas simultaneamente, ou videoconferências com até 10 


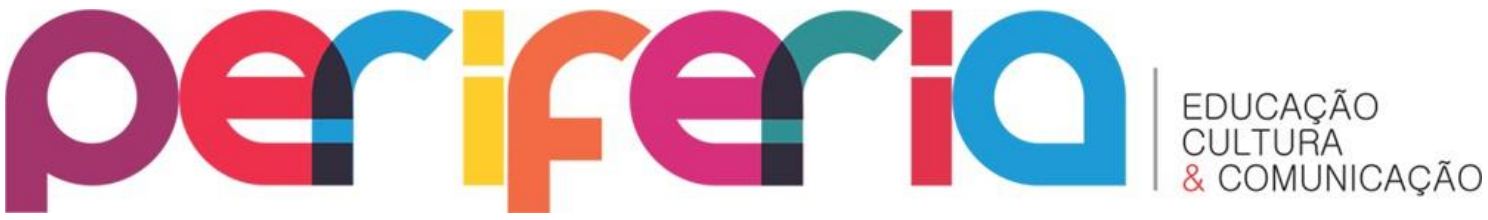

pessoas...em si, o Skype não traz nenhum grande avanço tecnológico que the seja exclusivo. Mas vem conseguindo concretizar a ficção do videofone ao combinar simplicidade de uso e custo baixo, desde que se disponha previamente de um computador com microfone, placa de som, alto-falantes e acesso à Internet em banda larga (BRAGA e GASTALDO, 2012, p. 8-9).

Importante ressaltar que qualquer interface traz implicações numa entrevista. Uma das questões que Braga e Gastaldo (2012) observam sobre o Skype é que o dispositivo inviabiliza o compartilhamento do mesmo ambiente físico e, consequentemente, a co-presença física imediata. Mais ainda, outros elementos da interação que estão acessíveis numa entrevista presencial, não são viáves via Skype. Por exemplo, gestos, posicionamentos corporais, cheiros e vestimentas não estariam acessíveis ou estariam apenas parcialmente, na medida em que o plano das tomadas de câmera normalmente fica num "plano médio fechado" e em "close-up" (BRAGA e GASTALDO, 2012).

$\mathrm{Na}$ minha pesquisa, o aplicativo facilitou o contato com professores em diversos bairros, de maneira rápida. Porém, houve problemas de conexão, falhas no áudio, disponibilidade de horário e, como muitos foram entrevistados à noite, em suas casas, houve algumas interrupções.

Mas o que realmente me instigou neste processo utilizando o Skype foi exatamente o que os autores mencionam sobre a impossibilidade da presença física do Outro. A distância, bem como os recursos que o aplicativo oferece, viabilizaram o ocultamento do rosto de alguns entrevistados, potencializando reflexões sobre o estrangeiro na relação entrevistador-entrevistado.

\section{OS DESAFIOS METODOLÓGICOS DA PESQUISA: “ESTRANGEIRO” EM CENA}

A bandeira "dar voz ao Outro" que comumente aparece nas pesquisas etnográficas caracteriza-se, no escopo teórico com o qual trabalho, por uma relação que não é neutra e instiga a abertura de um espaço que evidencie a luta em torno do poder de significar num contexto discursivo que jamais será 


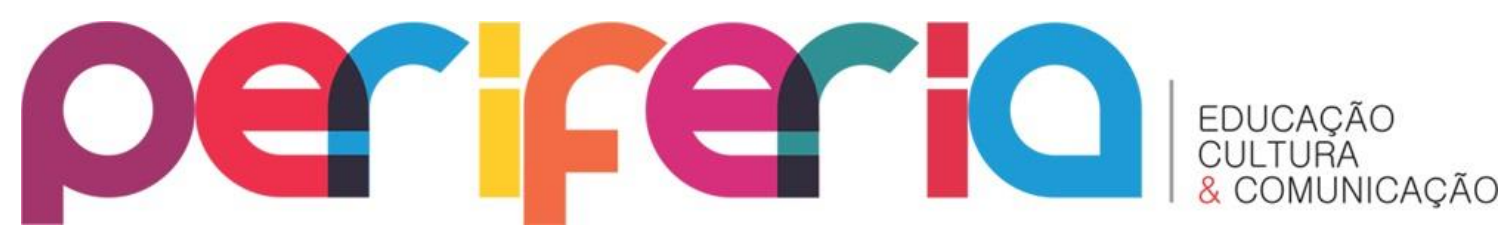

compreendido na sua totalidade. Como mencionei, trabalho sob a perspectiva de que dar voz ao Outro é reconhecer as múltiplas línguas, múltiplos sentidos dinamizados em fluxo contínuo. Neste sentido, reconheço que o Outro precisa ser ouvido em meio à produção de sentidos instáveis e antagônicos, sentidos esses que afloram constantemente e estão em permanente disputa por significação entre pesquisador e pesquisado.

Entre o discurso do sujeito a ser analisado e conhecido e o
discurso do pesquisador que pretende analisar e conhecer,
uma vasta gama de significados conflituais e mesmo
paradoxais vai emergir. Assumir esse caráter conflitual e
problemático da pesquisa em Ciências Humanas implica
renunciar a toda ilusão de transparência: tanto do discurso do
outro quanto do seu próprio discurso (AMORIM, 2003, apud
ROCHA, DAHER e SANT'ANNA, 2008, p. 12).

Mesmo ciente da impossibilidade de transparência, da impossibilidade de apreensão total de sentidos, de que esse processo é conflituoso e de que eu não era a detentora do saber, fui surpreendida pelo jogo de poder que, talvez, presencialmente, transcorresse de outra maneira. É importante deixar claro que, no meu entendimento, o jogo de significação acontece o tempo todo na pesquisa, independente da interface a ser utilizada ou da metodologia - entrevistas, análise de documentos. Mas a minha experiência com o Skype potencializou esse jogo.

Uma das professoras, solicitante da entrevista por Skype, havia ressaltado, numa conversa informal no Facebook, que esteve à frente do movimento grevista dos professores do Município do Rio de Janeiro no ano de 2014, lutando por questões relativas à valorização da categoria e, portanto, não gostaria de correr riscos que pudessem prejudicar sua carreira. Eu dei todas as garantias para o anonimato: seu nome seria trocado e não haveria gravação de imagem, somente de voz. Ela concordou. No dia da entrevista, a professora perguntou novamente, via Facebook, se haveria gravação da imagem. Respondi negativamente. Quando nos conectamos pelo Skype, a entrevistada apareceu no escuro. Ela ligou a câmera, mas desligou a luz do 


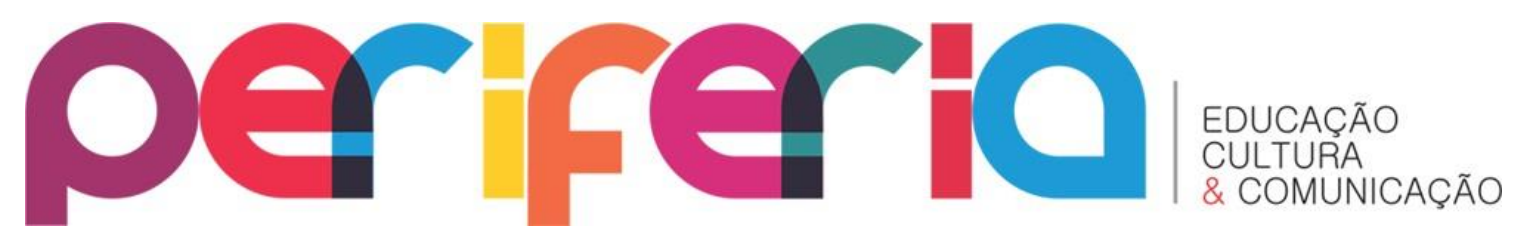

ambiente onde estava. Eu via a silhueta, os braços se mexendo, mas não via o rosto. E ela me via. Quando pedi para ela ligar a luz do ambiente onde estava, respondeu negativamente, sob a justificativa de que realmente não queria e não poderia se mostrar.

Nesta trajetória de entrevistas, essa foi a primeira pessoa que tomou a atitude de não aparecer, interrompendo o planejamento do processo. Com isso, ela inverteu a relação de poder entre entrevistador e entrevistado. Ainda que o pesquisador trabalhe sob a perspectiva teórica discursiva - com no meu caso -, considerando a produção dialógica de respeito ao Outro, ele está enredado no jogo de poder que faz parte das relações interpessoais. Vivenciamos o tempo todo esse poder e as diferenças se movem em função da disputa que nunca deixará de existir.

O Skype para a entrevistada, escondida na penumbra, não foi apenas uma interface tecnológica, mas um instrumento para o ato político. Ela "blasfemou”, blasfêmia aqui entendida, segundo Bhabha (2013), como o rompimento da tradição, reposicionando e reinscrevendo nossa relação entrevistador - entrevistado, ainda que eu estivesse trabalhando sob a perspectiva da impossibilidade de transparência nesse contato com o Outro. 0 ato de não se mostrar foi um ato político e, naquele momento, liberou as contingências, as incomensurabilidades da relação entrevistador entrevistado numa pesquisa acadêmica. Abriu um espaço de contestação discursiva, colocando essa relação num plano relativo e evidenciando que a tradução - a produção de sentidos sobre a pesquisa - não pertence somente ao pesquisador.

O entrevistado também está traduzindo, produzindo significados na prática da entrevista. A atitude criativa da professora, como atitude política, desconstruiu a tradição de entrevistas e deslocou o processo de identificação entrevistador - entrevistado, questionando e rompendo com a posição de pesquisadora, supostamente detentora do controle do processo. Houve uma ruptura no jogo político e os sentidos dessa relação se hibridizaram. No momento da entrevista, houve uma partilha de ações, concepções e os 


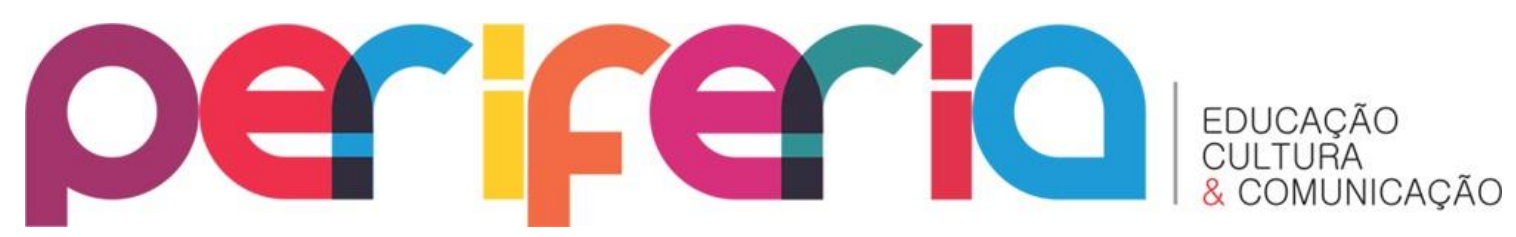

sentidos da pesquisa - nos seus diversos aspectos, inclusive sobre o objeto de estudo - tanscorreram ao mesmo tempo. De fato, a entrevistada problematizou a pesquisa dialógica, mediada por uma interface tecnológica. 0 Skype contribuiu para o jogo da diferença, para a criação de outras linguagens num processo que é fugidio, permeado por assimetrias de poder. A regra foi subvertida. (BHABHA, 2013).

O estrangeiro transitou neste processo, não só na referida entrevista como nas demais. Ainda que de maneira diferente dessa entrevistada, outros professores também não se mostraram, sob a justificativa de que a câmera não estava funcionando ou que não sabiam mexer no dispositivo. Mas todos concederam a entrevista, deixaram que a voz fosse ouvida e reinscreveram este processo. Dessacralizaram as transparências nos seus atos insurgentes de tradução da entrevista, quebrando a ordem e colocando-a no movimento de significação através do processo de diferimento, da criação. Ao subverterem, produziram o novo, traduziram (BHABHA, 2013), enriquecendo reflexões não apenas no que diz respeito aos objetos da pesquisa, mas sobre as possibilidades das interfaces tecnológicas nas pesquisas acadêmicas. O Skype viabilizou um espaço de negociação de sentidos, de ideias sobre o conceito de entrevista que talvez presencialmente não fosse possível ou não fosse percebido.

Espero provocar descolamentos nas reflexões sobre a abordagem teórico-metodológica. Os recursos tecnológicos, entre eles o Skype, utilizados como estratégias para a investigação, colaboraram para que minhas discussões sobre o referencial teórico da pesquisa. Com isso, enfatizo que a teoria e a metodologia caminham de maneira conjugada nas análises. Os recursos tecnológicos utilizados na investigação são parte inexorável de uma pesquisa que subsidiou reflexões sobre a performance de pesquisadores como entrevistadores. Mas, toda investigação é produzida no terreno indecidível, considerando as idas e vindas das ideias, dos sentidos, que se movimentam em meio a lutas por significação (DERRIDA, 1995; LACLAU, 1998 apud COSTA, CUNHA e LOPES, 2013). Neste sentido, pesquisadores são sempre estrangeiros 


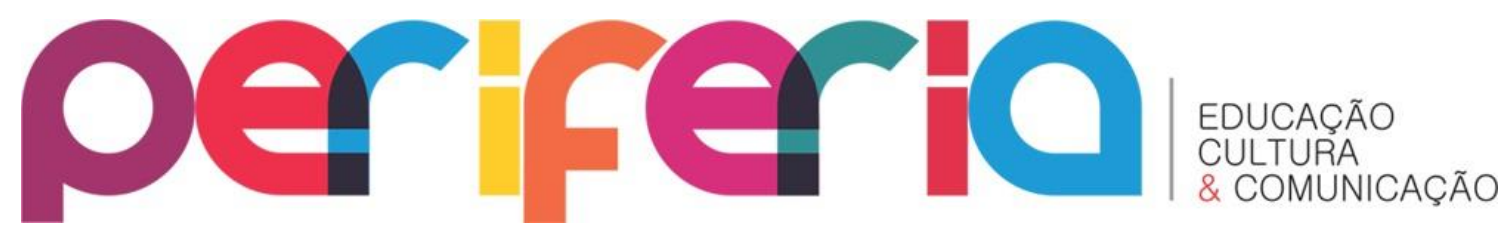

em cena. Atores sociais que contribuem para a desarticulação e se desarticulam o tempo todo, junto com seus objetos de pesquisa, seus entrevistados - também pesquisadores estrangeiros, reinventando sentidos também sobre pesquisas acadêmicas com interfaces tecnológicas.

\section{REFERÊNCIAS BIBLIOGRÁFICAS}

BAKHTIN, M. Marxismo e filosofia da linguagem. 12. ed.[S.I.]: Hucitec, 2006.

BHABHA, H. O local da cultura. 2. ed. Belo Horizonte: UFMG, 2013.

BRAGA, A.; GASTALDO, E. Variações sobre o uso do skype na pesquisa empírica em comunicação: apontamentos metodológicos. Contracampo, Niterói, v. 24, n. 1, 2012. Disponível em:

<http://www.uff.br/contracampo/index.php/revista/article/view/185>. Acesso em: 23 nov. 2014.

COSTA, H. H. C.; CUNHA, E. V. R.; LOPES, A. C. Da recontextualização à tradução: investigando políticas de currículo. Currículo sem Fronteiras, n. 3, 2013.

COSTA, A. M. N. D.; DIAS, D. R.; LUCCIO, F. D. Uso de entrevitstas on-line no método de explicitação do discurso subjacente (MEDS). Psicologia: Reflexão e Crítica, Porto Alegre, v. 22, n. 1, 2009. Disponível em:

<http://www.scielo.br/scielo.php?script=sci_arttext\&pid= S0102-

79722009000100006>. Acesso em: 21 nov. 2014.

DAHER, M. D. C.; SANT'ANNA, V. L. A.; ROCHA, D. A. entrevista em situação de pesquisa acadêmica: reflexões numa perspectiva discursiva. Polifonia, Mato Grosso, v. 8, n. 8, 2004. Disponível em: <http://periodicoscientificos.ufmt.br/ojs/index.php/ polifonia/article/view/1132>. Acesso em: 22 nov 2013.

DERRIDA, J. A escritura e a diferença. São Paulo: Perspectiva, 1995. Torres de Babel. Belo Horizonte: UFMG, 2006.

ESTERMANN, D.; PARAíSO, M. A. Metodologias de pesquisas pós-críticas em educação. In: - Metodologias de pesquisas pós-críticas ou sobre como fazemos nossas investigações. Belo Horizonte: Mazza Edições, 2013. 


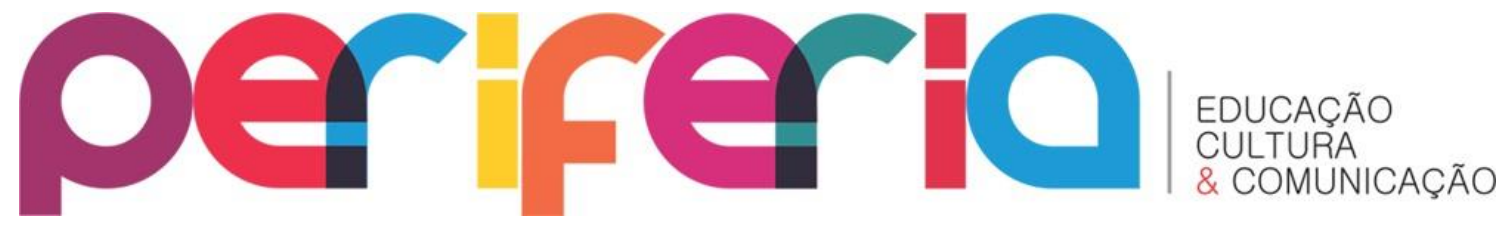

AS REDES SOCIAIS MAIS USADAS DO MUNDO. [site]. 2017. Disponível em: $<$ http://www.clickgratis.com.br/infograficos/tecnologia/as-redes-sociaismais-usadas-no-mundo.html>. Acesso em: 10 out. 2016. 